\title{
HERNIA REPAIR IN CIRRHOTIC PATIENTS
}

\author{
(Letter to the article "Abdominal and inguinal hernia in cirrhotic patients: what's the best \\ approach?" in ABCD Arq Bras Cir Dig. 2012; 25(1):52-55)
}

\section{TO THE EDITOR}

I have read the review article by Silva et al. ${ }^{3}$ with great interest and contentment because some seem to forget about the problem of hernias in cirrhotic patients ${ }^{1}$. Silva et al. ${ }^{3}$ included relevant literature and indeed more information is necessary and I am awaiting their announced randomised controlled study. However, the Title "Abdominal and inguinal hernia in cirrhotic patients: what's the best approach?" for me is misleading because their paper does not give an exact answer to the question and furthermore in the introduction section they do not say anything about the aims of this review article. To answer the question about the best approach it is not enough to discuss operation versus no operation or the timpoint for the operation (acute versus elective); it is moreover necessary to discuss different operation methods including the type of anaesthesia. I think there would be more cirrhotic patients eligible for elective surgery if for instance more procedures would be performed in local anaesthesia ${ }^{2}$. It would be very interesting if the authors could comment on this.

\section{REFERENCES}

1. Bernhardt GA, Mischinger HJ. Abdominal wall hernias as complications of cirrhosis. Liver Int. 2012 Mar;32(3):519-20.

2. Bernhardt GA. Inguinal Hernia Repair under Local Anaesthesia in Patients with Cirrhosis.World J Surg. 2012 Jun;36(6):1443-4.

3. Silva FD, Andraus W, Pinheiro RSN, Arantes-Junior RM, Lemes MPL, Ducatti $L$, D'albuquerque LAC. Abdominal and inguinal hernia in cirrhotic patients: what's the best approach? Arq.Bras.Cir.Dig. 2012 Jan-May;25(1):52-55.

Gerwin A. Bernhardt

From the Department of Surgery, Division of General Surgery Medical University of Graz, Graz, Austria and the Department of Surgery, Dictrict Hospital of Voitsberg, Voitsberg, Austria.

E-mail: gerwin.bernhardt@lkh-voitsberg.at or wintschgerl@gmail.com

\section{THE AUTHORS REPLY}

We thank Dr Bernhard for the interest in this field and for the interesting comments. We agree that there are differences in surgical technique and clinical management in non hepatic surgeries in cirrhotic patients. Indeed there are specificities in surgical technique, in anaesthesia and also in post operative management. However, we are not sure if the anaesthesia is local or general is going to make a big difference, and if anaesthesia is more implicated in inflammatory response or not in cirrhotic patients. Actually, we didn't look at this point. It is an interesting topic and maybe someone could study the issue prospectively.

Moreover, we are also worried about fluid management, ascitis leak, post operative hematoma, and post operative renal dysfunction, for example, in this kind of procedure in cirrhotic patients. We have also take into account the quality of life of these patients. Most of them have pain, physical disabilities and frequently they can barely walk when the hernia is inguinoescrotal.

The elective and urgent procedures are another point. Urgency is associated with renal dysfunction and infection, and for sure, patients coming with ascitis leaking and infection have higher morbidity and mortality. In addition, there is the byes that many urgent procedures are done in small inexperienced centres with worst outcome and we don't have this data.

Finally, we agree that It is indeed a complex issue and we have much to learn and improve. Anybody's effort is welcome because the disease has many variables and concerns, and the management of such patients are still a challenge even for experienced centres.

\section{REFERENCES}

1. Andraus W, Sepulveda A, Pinheiro RS, Teixeira AR, D'Albuquerque LA. Management of uncommon hernias in cirrhotic patients. Transplantation proceedings. 2010;42(5):1724-8. Epub 2010/07/14.

2. Andraus W, Paoletti B, Pinheiro RSN, Bitencourt FS, Farias CNF, D'Albuquerque LAC. Quality of life in patients with abdominal hernia and cirrhosis. Archives of Digestive Surgery. 2009;22(4):222-5.

3. Marsman HA, Heisterkamp J, Halm JA, Tilanus HW, Metselaar HJ, Kazemier G. Management in patients with liver cirrhosis and an umbilical hernia. Surgery. 2007;142(3):372-5.

Wellington Andraus

From Liver and Digestive Organs Transplant Unit, Department of Gastroenterology, University of Sao Paulo School of Medicine, Brazil.

E-mail: wellington@usp.br / wandraus@terra.com.br 